\title{
Boundary Capabilities in MNGs: Knowledge Transformation for Creative Solution Development
}

\section{Esther Tippmann, Pamela Sharkey Scott and Andrew Parker \\ University College Dublin; Maynooth University-National University of Ireland Maynooth; University of Exeter Business School}

ABSTRACT The management of knowledge across country units is critical to multinational corporations (MNCs). Building on the argument that boundary spanning leads to the development of creative problem solving outcomes, this study advances the concept of MNG knowledge transformation and examines its relationship with solution creativity. Using questionnaire data on 67 problem solving projects, we find that opportunity formation is an underlying mechanism linking MNG knowledge transformation to the development of creative solutions. These insights contribute to our understanding of boundary spanning in global organizations by substantiating MNC knowledge transformation and elaborating the relationship between boundary spanning and creative solution development. If successful at knowledge transformation, collaborators from across the MNC can construct previously unimagined opportunities for the generation of creative outcomes.

Keywords: boundary spanning, knowledge transformation, MNE/MNG management, opportunity formation, problem solving, subsidiaries

\section{INTRODUGTION}

For multinational corporations (MNGs), competitive advantage rests on utilising their most valuable resource, the diverse knowledge located in dispersed headquarters and subsidiaries to generate creative and innovative outcomes (Bartlett and Ghoshal, 1989; Doz et al., 2001; Kogut and Zander, 1993). The challenge for MNCs, however, is unlocking this diverse knowledge, as the underlying specializations and context sensitivities make it difficult to apply this knowledge in new ways when collaborating across the organization (Mudambi, 2011). To generate creative or innovative outcomes in this complex setting, collaborators from MNG units located in different countries need to

Address for reprints: Esther Tippmann, Assistant Professor, Department of Management, University College Dublin, Michael Smurfit Graduate Business School, Dublin, Ireland (esther.tippmann@ucd.ie). 
find ways to draw on and interlink their diverse knowledge. The ability of collaborators to span the boundaries that separate their diverse knowledge is critical.

To date, explorations of the challenges of managing knowledge in MNGs have largely investigated the pattern of knowledge flows (e.g., Gupta and Govindarajan, 2000; van Wijk et al., 2008), or the search activities of locating and accessing dispersed knowledge (Parker and Tippmann, 2016; Tippmann et al., 2014). In addition, work on innovation within the MNC recognizes the value of utilizing diverse knowledge across country units (Berry, 2014; Mors, 2010; Mudambi et al., 2007). Yet, the implicit boundary spanning work (Schotter et al., 2017), in particular the action and interaction required to successfully deal with diverse knowledge, is not sufficiently theorized. Similarly, research concerned with boundary spanning in the MNC context has thus far focused on the role and skills of individual boundary spanners (Barner-Rasmussen et al., 2014; Schotter and Beamish, 2011) in connecting different knowledge pockets, and on the role of communities of practice in the access and dissemination of tacit knowledge (Tallman and Chacar, 2011). Despite this progress, there remains a gap in our understanding of the boundary spanning behaviours of individuals when working together as a group across geographically distributed MNG units. Little is known about how collaborators from across subsidiary and headquarters units collectively mobilize their unique and specialized knowledge to achieve boundary spanning. In sum, there is a need to examine the microsocial activities of collaborators from different geographically dispersed locations as they seek to apply their knowledge in new and useful ways and the specific mechanisms that govern the impact of these boundary spanning efforts on the generation of creative or innovative outcomes.

To address this gap, we draw on seminal work by organization scholars, who have explored more deeply the micro-social interactions of collaborators with diverse knowledge backgrounds in the context of innovation projects (e.g., Carlile, 2002, 2004; Dougherty, 1992). This work suggests that boundary spanning is at the heart of the generation of innovative and creative outcomes during problem solving. However, transferring knowledge in the sense of 'simple' processing of information, or even translating knowledge in the sense of developing a common meaning to overcome interpretive differences between contexts is insufficient for solving non-routine problems. Instead, knowledge transformation is required, that is a systematic approach by individuals to utilize, learn from and synthesize knowledge at boundaries (Carlile, 2004; Carlile and Rebentisch, 2003). This necessitates active and deep engagement to modify common and individual domain-specific knowledge to effectively share and synthesize knowledge at the boundary. If collaborators succeed in this demanding task and exhibit a capacity and ability to act and interact in a manner which iteratively and repeatedly transfers, translates and transforms knowledge, then a boundary capability is developed (Carlile, 2004). Such a boundary capability enables effective utilization of a firm's diverse knowledge for the generation of creative and innovative outcomes.

Following this, we propose the concept of $M N C$ knowledge transformation as one underpinning of a boundary capability in the MNC, capturing the behavioural aspects of collaborators' actions and interactions in applying diverse knowledge across subsidiary and headquarters units in situations where innovative or creative outcomes are desired. Combining arguments from problem solving theory (Baer et al., 2013; Nickerson et al., 
2012) and the literature on opportunity creation (Alvarez and Barney, 2007; Alvarez et al., 2013), we further argue that opportunity formation, defined as the extent to which collaborators explore new possibilities and construct new ideas, is a generative or mediating mechanism through which MNG knowledge transformation leads to creative solutions. Breaking out of habitual and common problem definitions is a key challenge in problem solving (Baer et al., 2013, Enders et al., 2016; Ford, 2002). Therefore, we propose that opportunity formation, as an entrepreneurial approach to problem formulation, stimulates the oftentimes lacking, but critically important, activities of reframing or redefining a situation. This in turn leads to the development of previously unimagined solutions. Our interest is in the level of creativity of the final, implemented solution (Godart et al., 2015), defined as the degree to which the solution exhibits the two attributes of creativity - newness and appropriateness (Amabile, 1996; Oldham and Cummings, 1996; Perry-Smith and Shalley, 2003). A creative solution thus combines novelty and efficacy, meaning that while different to previous solutions, it is not too bizarre to prevent adoption by the firm. We test our theoretical model by examining 67 nonroutine problem solving processes (Cyert and March, 1963; Nelson and Winter, 1982) at a project-level of analysis.

By finding empirical support for our arguments, this study contributes to theory in important ways. First, we respond to calls to draw on theories of boundary spanning to advance the MNG literature (Andersson et al., 2016). Specifically, by conceptualizing MNC knowledge transformation as capturing the micro-social actions and interactions of collaborators across MNC units as they seek to apply their diverse knowledge in new ways, we address a hitherto neglected perspective of boundary spanning in MNCs. Our findings demonstrate that knowledge transformation can be the collective accomplishment of a group of collaborators from different MNG units. Such a perspective on boundary spanning in global organizations is greatly needed given the rise of projectlevel organizing to perform innovative and creative activities. In addition, our finding that the micro-social interactions of collaborators lead to the collective achievement of creative solutions suggests that knowledge transformation is one critical microfoundation of a boundary capability in the MNC.

Second, our findings confirm the value of boundary spanning for the attainment of creative solutions (e.g., Carlile, 2002, 2004; Dougherty, 1992) and offer interesting insights into this association. We develop arguments and find empirical support for a more complex association than previously considered: the influence of knowledge transformation on the development of creative solutions is unlocked by the mediating effect of collaborators reframing a problem as an opportunity. Knowledge transformation is the most demanding activity in spanning boundaries during problem solving (Carlile, 2004), and our results imply that proposing and applying diverse knowledge in new ways across MNC units enables the exploration of alternative problem formulations and unearths new solution options. Opportunity formation offers new possibilities for generating novel and useful products, services or processes. Our study thus provides new insights into the underlying mechanisms of how the difficult task of spanning boundaries in the MNG adds value.

Our third contribution is to reveal a path for subsidiaries to achieve creative contributions for the MNC. Despite acknowledging that subsidiaries can be creative (Cantwell 
and Mudambi, 2005, 2011; Scott et al., 2010), there is a lack of research investigating the specific ways in which creative solutions are achieved. Our findings show that creative outcomes in the MNC can be the result of a collective activity spanning different units, complementing discussions focused on competence creating subsidiary mandates with arguments related to the collective, behavioural accomplishments of a diverse group of MNC collaborators. Last but not least, our study has implications for the literature on opportunity formation in established firms as well as insights for management practice.

\section{THEORY AND HYPOTHESES}

\section{MNG Boundary Spanning Gircumstances and Boundary Gapability}

We build on the theory of boundary spanning knowledge processes in situations where innovative or creative outcomes are desired. Then, the kind of boundary and corresponding challenges of boundary spanning depend on the degree of difference and dependence of knowledge between the various individuals engaged at the boundary as well as the extent to which the situational circumstances are atypical, differing from usual circumstances (Carlile 2004; Carlile and Rebentisch, 2003). We will now identify how differing circumstances lead to variation in the relative complexity of boundary spanning in the MNC context.

In the MNC, units located in different countries possess and nurture specialized and context-specific knowledge that may lead to various degrees of difference and dependence between headquarters-subsidiary as well as between subsidiary-subsidiary knowledge. In relation to the degree of difference in knowledge between MNC units, each subsidiary possesses a unique stock of knowledge, influenced by its mandate and associated capabilities (Ghoshal and Bartlett, 1990). This means that geographic distribution causes specialized knowledge pockets. In addition, each subsidiary follows an idiosyncratic pattern of knowledge development in response to its local cultural, administrative and economic environment (Ghemawat, 2001; Kostova and Zaheer, 1999). In particular, external interactions with local organizations can lead to highly specialised and context-specific knowledge (Mudambi and Swift, 2009), increasing the degree of difference in knowledge between MNC units. Considering the degree of dependence of knowledge in the MNC, value creation in such organizations depends to a large extent on managing the multiple inter-relationships between these different and geographically distributed knowledge pockets. It is, therefore, fundamental to reintegrate specialized, yet interdependent knowledge across units (Doz et al., 2001; Ghoshal and Bartlett, 1990). Typical examples of high dependencies in knowledge across MNC units include international interdependencies at different stages in the global value chain and international co-development settings.

Carlile (2004) suggests that if the differences and dependencies in knowledge are known by the individuals involved at the boundary, a common lexicon is developed that adequately facilitates knowledge sharing at the boundary. In such situations, the complexity of the boundary is relatively 'unproblematic': it is a syntactic boundary that can be crossed where there is an adequate capacity to process information when transferring 
knowledge (Galbraith, 1973; Lawrence and Lorsch, 1967). Many studies on knowledge transfer in the MNC have adopted this information processing perspective (e.g., Gupta and Govindarajan, 2000; Szulanski, 1996), assuming that stable conditions in the difference and dependency of knowledge between headquarters-subsidiary or subsidiarysubsidiary knowledge enable the creation of a common lexicon, which in turn functions as common knowledge between MNC units to effectively transfer knowledge at these syntactic boundaries.

However, if the situational circumstances are atypical to some extent, certain differences and dependencies in knowledge at the boundary become unclear or ambiguous. This leads to different interpretations among individuals and leads to, what is called, a semantic boundary (Carlile, 2004). Such atypical circumstances occur when facing different requirements, in the $\mathrm{MNC}$, for example, distinct or changing local environments, and/or when working with unknown individuals as is typical in task-specific international or global teams where individuals with certain expertise or competences are brought together from various MNC units. To address the consequent interpretive differences at semantic boundaries in the MNC, a common meaning needs to be developed to effectively translate knowledge across boundaries (Carlile, 2004; Dougherty, 1992; Nonaka, 1994). Evidence of considerable efforts by individuals to dis-embed and re-contextualize localized and embedded knowledge in the MNC to make it meaningful and actionable in a different context (Erkelens et al., 2015; Noorderhaven and Harzing, 2009) as well as activities of communities of practice (Tallman and Chacar, 2011) are examples of knowledge translation in the MNC.

Last but not least, there are situations that are highly atypical, which are a commonplace scenario in settings where innovative or creative outcomes are desired. Such situations cause the most complex form of boundary - called a pragmatic boundary (Carlile, 2004), and reveal the different interests of individuals at the boundary. This hinders their established ability to share knowledge. To effectively utilise knowledge across pragmatic boundaries thus requires a more engaged and deeper sharing than 'simply' transferring or translating knowledge between different contexts. Knowledge needs to be actively transformed to suit the specific situation at hand (Carlile and Rebentisch, 2003). In addition, to effectively utilize their diverse knowledge, individuals need to propose and apply knowledge in new ways (Carlile, 2002, 2004). To this end, individuals need to learn about the consequences of one's own knowledge and require a willingness and ability to modify one's own knowledge to achieve a novel synthesis (Bechky, 2003; Levina and Vaast, 2005; Pawlowski and Robey, 2004). Knowledge transformation also involves trying new alternatives, putting individual knowledge 'at stake', and accepting that some of it may be changed or abandoned (Carlile, 2004). The knowledge used at pragmatic boundaries then becomes a 'transformed mixture' of the knowledge deemed valuable and of consequence to the specific situation (Carlile, 2004, p. 559). In addition, the uniqueness of the situation requires a political approach whereby a new common interest between actors needs to be negotiated to provide an adequate means for sharing knowledge. Coopetition structures in the MNG - the duality of cooperative and competing arrangements between subsidiaries (Luo, 2005; Tsai, 2002), combined with usual pressures from headquarters to both integrate with the organization while demonstrating subsidiary-specific value (Mudambi, 2011), may amplify the political aspects of 
spanning pragmatic boundaries. The ability to negotiate different interests and trade off ideas to create a common interest across MNC units thus becomes critical to serve as a foundation for adequately sharing knowledge. Combining these arguments, we propose the concept of $M \mathcal{N} C$ knowledge transformation as the extent to which collaborators from different MNC units propose and apply in new ways one another's diverse knowledge at pragmatic boundaries.

Having discussed the various circumstances that can arise at boundaries in the MNC, it is evident that achieving innovative or creative outputs requires systematically managing knowledge at boundaries of various complexity, ranging from semantic, to syntactic, and pragmatic in terms of increasing boundary complexity. To this end, a boundary capability is needed (Carlile, 2004), defined as the repetitive and iterative approach of collaborators to not only transfer and translate knowledge, but to transform knowledge in atypical situations for application in new ways for solution development. By overcoming the challenges of divergent and different interests when working together, we conjecture that such a boundary capability enables the MNG to utilize and exploit the value of its diverse but geographically dispersed knowledge.

\section{MNG Knowledge Transformation, Opportunity Formation, and Creative Solutions}

The focus of this study is non-routine problem solving. Given that such complex problem solving occurs in response to situations that are atypical to the firm (Cyert and March, 1963; Nelson and Winter, 1982) and requires the reconciliation of divergent interests as well as the interlinking of diverse sets of knowledge in new ways (Nickerson and Zenger, 2004), the crossing of pragmatic boundaries becomes important. Thus, we now develop arguments that link MNC knowledge transformation to the generation of creative solutions.

Problem solving comprises both problem formulation, in terms of understanding and defining a problem, and solution development, in terms of designing and implementing a solution. Prior literature on boundary spanning during problem solving, however, typically examines the value of knowledge transformation on the solution development aspect of problem solving and does not explicitly explore the preceding problem formulation (e.g., Carlile, 2004; Carlile and Rebentisch, 2003). A notable exception is the study by Bechky (2003), who describes how transformational knowledge exchange can recontextualize a problem to arrive at a shared problem understanding. Due to the central influence of problem formulation on shaping the direction of subsequent solution development (Baer et al., 2013; Nutt, 1992, Simon, 1973; Simon and Hayes, 1976), we also focus on the effect of the problem formulation aspect. We suggest that knowledge transformation is critical to achieving a comprehensive framing when solving challenging problems at boundaries within the MNC. This leads us to argue a more complex association between knowledge transformation and the generation of creative outcomes, and to propose that this relationship is mediated by opportunity formation.

Formulating complex problems is challenging and no single actor's knowledge covers all aspects of a problem (Baer et al., 2013; Lyles, 1981; Newell and Simon, 1972). In addition, problems are not objectively defined but socially constructed 'from the 
knowledge available at a certain point in time and context' (Nonaka, 1994, p. 28). Alternative problem framings may emerge if solution ideas are not imposed and the generation of new options is encouraged (Lopez-Vega et al., 2016; Nutt, 1993, 2004). This suggests that bringing together diverse inputs from individual collaborators can benefit the comprehensiveness of problem formulation, specifically the extent to which alternative, yet equally valid problem formulations are generated (Baer et al., 2013; Nutt, 1984).

Bringing collaborators together for problem formulation activities, for example, by gathering individuals from various subsidiary and headquarter units, generates substantial capacity for building on diverse inputs. However, it is also likely to amplify collaboration impediments (Baer et al., 2013), which may, in some circumstances, inhibit the generation of alternative problem formulations. It can, for example, lead to power imbalances whereby powerful collaborators push to reuse certain knowledge, thus constraining the ability of other individuals to exploit the boundary spanning situation to generate more novel ideas (Carlile, 2002, 2004). In addition, there is a heightened danger of task conflict and breakdown in collaboration because of considerable difficulties in interacting and communicating in boundary spanning situations despite the good intentions of collaborators to share knowledge across such pragmatic boundaries (Bechky, 2003; Carlile, 2004; Dougherty, 1992; Leonardi, 2011). It has been suggested that such impediments result in the generation of fewer problem formulation alternatives (Baer et al., 2013), constraining problem formulations within a narrow or existing range of options. Problem formulation can thus benefit tremendously from effective boundary spanning enabled by the micro-social activities of individuals collectively achieving knowledge transformation.

The debating and engaged interaction typical for knowledge transformation may avoid the narrow or rushed analysis and lack of synthesis of root causes which lead to inadequate initial definitions (Lyles, 1981) and constrain solution finding to arriving at 'only' an effective approach (Lyles and Mitroff, 1980; Spradlin, 2012). In addition, deep transformational knowledge sharing has the capacity to more fundamentally reframe the problem (Mintzberg and Westley, 2001). By identifying and representing different knowledge and learning about differences across boundaries, knowledge can be applied in new ways to enable collaborators to reframe their past experiences. This allows a 'richer' understanding of the problem to be gained (Beck and Plowman, 2009), may trigger new interpretations that change previous problem conceptions (Hargadon and Bechky, 2006; Nutt, 1993), and may expand problem formulation to embrace broader purposes (Volkema, 1983). Such proposing and application of specialized knowledge may also stimulate 'thinking outside the box' (Ford, 2002; Gavetti and Levinthal, 2000) by synthesizing the diverse knowledge contributed in new ways. The 'creative abrasion' (Leonard-Barton, 1995) which can arise during knowledge transformation allows individuals to propose divergent and more novel forms of knowledge that help to shed new light on a problem, its root causes and can ultimately generate alternative problem formulations. By not only bringing together diverse inputs, but producing a novel synthesis, knowledge transformation allows alternative problem formulations to emerge - to generate problem formulations that look beyond the habitual, to generate ideas for improving and innovating. This aligns well with arguments that through activities of accessing, 
learning from and utilizing diverse knowledge an opportunity can emerge (Alvarez and Barney, 2007; Alvarez et al., 2013; Barreto, 2012; Mitchell et al., 2008). We thus propose that knowledge transformation can result in collaborators exploring and generating new and alternative problem formulations - problems may be formulated as opportunities.

Following this, we suggest that MNC knowledge transformation enables opportunity formation as it modifies the contributions of collaborators across pragmatic boundaries within MNGs to generate new problem formulations. Subsidiary driven problem solving can exhibit strong tendencies to formulate problems within local and context-specific constraints (Tippmann et al., 2012). The value of MNG knowledge transformation in breaking out of such narrow and habitual problem formulation can be illustrated with an example of an atypical situation experienced by one of the organizations that participated in our study, a French subsidiary. This unit, mandated with developing and manufacturing new products for developed markets, was challenged to significantly lower the cost of its products to improve margins. A narrow formulation of this problem suggests that the subsidiary would adopt its usual definition of the root cause; cost of some supplies or inefficiencies in the production process. In this example, however, the French subsidiary engaged with a broad range of diverse collaborators from other MNC units to work together and pursue knowledge transformation intensely from the outset.

The French subsidiary managers identified colleagues in a sister R\&D subsidiary in Asia who had innovated new product platforms for emerging markets. Although the collaborators from the French and Asian subsidiary shared some new product development knowledge, as different product platforms were involved, differences and dependencies in knowledge became ambiguous, requiring knowledge transformation to span this boundary effectively (Carlile, 2004). The French subsidiary managers also involved the global marketing team at the US headquarters, bringing to the fore the political aspect of MNG knowledge transformation. The primary interest of the French subsidiary was margin improvement, while the global marketing experts were concerned with maintaining the premium positioning of the product. The same problem could have been formulated narrowly as a cost issue or as a marketing challenge. However, through iterations of proposing knowledge and learning about differences, facilitated by headquarter managers engagement in 'lubricating' activities to improve interactions (Birkinshaw et al., 2017), the collaborators moved from a narrow problem formulation and the idea of opening up a new market segment with the proposed lower cost product platform emerged - the problem was reframed as an opportunity. In sum, knowledge transformation can lead collaborators across MNC pragmatic boundaries to explore and generate alternative problem formulations and reshape problems as opportunities.

Hypothesis 1: MNC knowledge transformation is positively associated with opportunity formation.

Our first hypothesis is concerned with activities during problem formulation and we now develop the argument that opportunity formation serves as the conduit by which MNG knowledge transformation contributes to solution creativity. Problem solving proceeds backwards from the 'goal state' (Cyert and March, 1963; Felin and Zenger, 2016) 
of an envisioned solution (Nutt, 1984, 2005) that guides the efforts of the problem solvers. Having expanded problem formulations by a variety of new possibilities, the spectrum of conceivable outcomes increases to embrace more novel and appropriate solutions. This means that the potential for solution development expands as efforts are directed beyond the root problem towards attaining a solution that responds to an identified opportunity. However, potential creative solutions still need to be realized and may not be enacted or fall short of successful responses for a variety of reasons. In complex organizations such as MNGs, these include ineffective issue selling (Dutton and Ashford, 1993), political resistance (Dörrenbächer and Gammelgaard, 2006), failing to overcome the 'not invented here syndrome' (Birkinshaw and Ridderstrale, 1999) or to win senior management approval, and the absence of a supportive organizational context (Burgelman, 1983). The translation of formed opportunities to enacted creative solutions cannot be taken for granted. At the same time, as collaborators from different MNG units repeatedly apply their diverse knowledge to attain an envisioned solution; solutions then 'emerge endogenously within a process of interactive human action' (Sarasvathy et al., 2010, p. 155). While collaborators are still required to resolve the initial organizational challenge that triggered the problem solving efforts, thus working towards attaining an appropriate solution, the broader perspective of opportunity formation allows for the 'proliferation and branching' of solutions (Collins, 2005, p. 211) and for the emergence of 'new means, ends, or means-ends relationships' (Eckhardt and Shane, 2003, p. 336). This is likely to increase the novelty of solutions (Aldrich and Martinez, 2010). Thus, opportunity formation allows the benefit of MNC knowledge transformation to be realized because individuals collaborating from across the MNG are unified by a common interest to generate a solution that has the required newness to fill the identified gap. In this sense, formed opportunities represent a concrete means for headquarters and subsidiary collaborators to apply their unique knowledge in new ways for the generation of novel outcomes. Compared to a final outcome that 'merely' represents a workable or habitual solution to a problem, the novelty of the solution now reflects both the knowledge diversity of collaborators from across the involved MNC units and the reformulated problem definition to achieve an outcome that combines novelty and usefulness.

In the context of our earlier example, reframing of the French subsidiary's initial problem, the need to reduce costs and improve margins, as an opportunity led to the exploration of new solutions to deliver on the identified opportunity. The final solution, achieved by bringing together knowledge from various MNC units, not only increased margins, but created a new market segment in developed markets for 'good value' products. This solution was particularly creative for this MNC given the unusual direction of technology transfer from emerging to developed markets that formed part of solution development and because it exploited untapped market potential, generating new revenue streams.

In sum, we argue that the emergence of new solutions is stimulated through opportunity formation, while the need to address the initial problem simultaneously pushes towards the attainment of appropriate solutions.

Hypothesis 2: Opportunity formation is positively associated with solution creativity. 


\section{METHODS}

\section{Sample of Problem Solving Projects}

A distinct feature of investigating problem solving processes is using the problem solving project as the level of analysis (Obstfeld, 2012). These projects are initiated as a response to an organizational problem, defined as 'a deviation from a desired set of specific or a range of acceptable conditions resulting in a symptom or a web of symptoms recognized as needing to be addressed' (Baer et al., 2013, p. 199). Given the atypical nature of nonroutine problems, they lend themselves to the investigation of knowledge transformation at pragmatic boundaries. We sampled 67 such problem solving projects. This sample size compares well with other studies that examined complex, organizational projects or initiatives (Ciabuschi et al., 2011; McGrath, 2001).

The problem solving projects in our study were undertaken by 29 subsidiary units of 27 MNGs and are located mostly in Ireland, but also in France and the UK. The chosen subsidiary units exhibited good variance in a range of characteristics at the unit, subsidiary and corporate level increasing external validity. First, at the corporation level, the MNCs operated in highly to moderately dynamic industries of ICT, pharmaceutical, building materials and social media, where organizational challenges regularly trigger problem solving processes. The MNGs also have different countries of origin (France, Germany, UK, USA and Sweden) to enhance cross-national coverage. Second, we aimed to introduce constructive variation at the subsidiary unit level. In the context of MNC value chain disaggregation and more 'fine-sliced' subsidiary mandates, each unit at the subsidiary may be characterized by a unique organizational context, making it more appropriate to consider the specifics of each unit rather than subsidiary level aggregations (Rugman et al., 2011). The chosen subsidiary units varied in their age, size, mode of establishment and function. Table I summarizes the characteristics of the subsidiary units that were used as a platform for investigating problem solving projects.

For each subsidiary unit, the unit manager (usually the General Manager, Managing Director or Director) identified all the relevant projects, i.e., created a representative list of projects that fitted our sampling criteria. To ensure consistency in identifying problem solving projects, the predetermined sampling criteria included: (1) the problem was nonroutine, that is an atypical situation for which the organization did not at that time have a pre-determined response (Cyert and March, 1963; Newell and Simon, 1972), (2) the problem solving process was completed or terminated within the past 12 months, a recent timeframe that reduces retrospective bias (Huber and Power, 1985), and (3) the problem solving efforts were initiated at the subsidiary level (rather than at headquarters or another unit). We emphasized that the problem solving project selected should include projects deemed more or less successful to reduce potential success bias. Following this procedure, 67 problem solving projects were identified with an average of 2.3 per subsidiary unit, with a range of 1 to 8 . They originated in different functional areas, including $\mathrm{R} \& \mathrm{D}$ (eight processes, 11.9 per cent), manufacturing (23 processes; 34.3 per cent), marketing/sales (20 processes, 29.9 per cent), services/support (seven processes, 10.4 per cent), supply chain/logistics (four processes, 6.0 per cent), finance (three processes, 4.5 per cent), and HR (two processes, 3.0 per cent). The problem solving projects 
Table I. Summary of characteristics of subsidiary units selected for study

$\operatorname{MNC}$ level $(\mathcal{N}=27)$

Industry

ICT $=16(59 \%)$

Pharmaceutical $=8(30 \%)$

Social media $=2(7 \%)$

Size (turnover in US\$)

Building materials $=1(4 \%)$

Size (employees)

Country of origin

Average $=33.4 \mathrm{bn}(\mathrm{SD}=37.5 \mathrm{bn})$

Average $=74,400(\mathrm{SD}=103,860)$

$\mathrm{US}=21(78 \%)$

$\mathrm{UK}=2(7 \%)$

Germany $=2(7 \%)$

France $=1(4 \%)$

Sweden $=1(4 \%)$

Subsidiary unit level $(\mathcal{N}=29)$

Location

Ireland $=26(90 \%)$

$\mathrm{UK}=2(7 \%)$

France $=1(3 \%)$

Age (years)

Size (employees)

Mode of establishment

Average $=13(\mathrm{SD}=10)$

Average $=410(\mathrm{SD}=660)$

Greenfield $=24(83 \%)$

Acquisition $=5(17 \%)$

focused on key organizational challenges of the subsidiary unit and often of the wider corporation and included replacing legacy processes, replacing legacy products/services, and rejuvenating management/business practices. Table II provides an overview of the sample and offers descriptive information that illustrates the variation in problem solving projects included in this study.

\section{Data Collection}

We collected data from August 2012 till November 2013 via paired surveys to capture information on the problem solving activities and outcomes, and the organization. To encourage participation, subsidiary top managers endorsed the study and we offered to share a feedback report and to invite participants to a workshop. Combined with guaranteeing confidentiality and the anonymity of organizations, a response rate of 100 per cent of the respondents contacted was achieved. To minimize common methods bias, data on the problem solving process was collected from the project leader(s), while information on the outcomes and organizational level variables was collected through a personally addressed email survey of the project leader's senior colleague and/or subsidiary top manager. In total, 72 project leaders participated (two project leaders participated for five projects), 40 managers evaluated problem solving outcomes (some managers rated the solutions of multiple projects), and 28 managers completed the subsidiary organization survey. Before conducting the final surveys, the face validity of the survey items was assessed by a panel of nine experts, comprised of five academic and four 
Table II. Description of problem solving projects

\begin{tabular}{|c|c|c|}
\hline Problem solving project type & Typical examples & Proportion in sample \\
\hline Replacing legacy processes & $\begin{array}{l}\text { A need to reduce costs or increase efficiency/ } \\
\text { quality through: } \\
\text { - Redesigning/creating new processes } \\
\text { - Standardizing current processes } \\
\text { - Developing automated processes and } \\
\text { required tools }\end{array}$ & $41.8 \%$ \\
\hline $\begin{array}{l}\text { Replacing legacy prod- } \\
\text { ucts/services }\end{array}$ & $\begin{array}{l}\text { A need to respond to shifting market needs } \\
\text { through: } \\
\text { - Updating products/services } \\
\text { - Designing/developing new market } \\
\text { solutions }\end{array}$ & $19.4 \%$ \\
\hline $\begin{array}{l}\text { Rejuvenating manage- } \\
\text { ment/business practices }\end{array}$ & $\begin{array}{l}\text { A need to increase efficiency/speed to mar- } \\
\text { ket/quality through: } \\
\text { - Transforming practices/routines } \\
\text { - Renewing/developing new competences }\end{array}$ & $38.8 \%$ \\
\hline
\end{tabular}

Note: $\mathrm{N}=67$.

subsidiary managers. Necessary amendments were undertaken to ensure clarity of questions.

In contrast to mail questionnaires, our method ensured that the project leaders that were selected had primary responsibility for pursuing the solution finding and intimate knowledge of the process. We also collected data from a senior colleague that was able to offer an independent evaluation of the problem solving outcomes. Furthermore, the person most knowledgeable about the subsidiary organization provided information about the unit's and subsidiary's behavioural context. To further increase the reliability of responses, the survey for the project leaders was interviewer administered, mostly in face-to-face meetings that lasted approximately one hour, with some lasting close to two hours. This allowed us to provide any clarification required. In the five cases where more than one project leader was appointed, we interviewed both project leaders simultaneously to achieve an agreed answer to our survey questions.

\section{Measures}

Table III offers descriptive statistics for all our items and item wording for the latent variables included in our model. The questions for the latent variables were asked using a 7-point Likert scale. We adapted existing measures wherever possible but also found it necessary to create new ones, as outlined below.

Solution creativity. The degree of solution creativity is most accurately assessed in relation to established solutions at the subsidiary level - the most proximate outcome. We used 
Table III. Operationalization of variables and descriptive statistics

\begin{tabular}{|c|c|c|c|}
\hline Construct and indicators & Mean & $S D$ & Label \\
\hline Solution creativity ${ }^{\text {a }}$ & 5.85 & 0.75 & SC \\
\hline $\begin{array}{l}\text { 'How ORIGINAL and PRACTICAL was the work of the } \\
\text { people involved in the problem solving? Original and } \\
\text { practical work refers to developing ideas, methods, or } \\
\text { products that are both totally unique and especially use- } \\
\text { ful to the organization'. }\end{array}$ & 5.75 & 1.01 & SC1 \\
\hline $\begin{array}{l}\text { 'How ADAPTIVE and PRACTICAL was the work of the } \\
\text { people involved in the problem solving? Adaptive and } \\
\text { practical work refers to using existing information or } \\
\text { materials to develop ideas, methods, or products that are } \\
\text { useful to the organization'. }\end{array}$ & 6.10 & 0.70 & SC2 \\
\hline $\begin{array}{l}\text { 'How CREATIVE was the work of the people involved in } \\
\text { the problem solving? Creativity refers to the extent to } \\
\text { which the employees developed ideas, methods, or prod- } \\
\text { ucts that are both original and useful to the } \\
\text { organization'. }\end{array}$ & 5.70 & 1.09 & SC3 \\
\hline$M \mathcal{N} C$ knowledge transformation ${ }^{\text {a }}$ & 5.10 & 1.31 & KT \\
\hline $\begin{array}{l}\text { 'Explaining the meaning of technical knowledge to col- } \\
\text { leagues from other units'. }\end{array}$ & 4.84 & 1.40 & KT1 \\
\hline $\begin{array}{l}\text { 'Sharing unit-specific knowledge to establish a shared mean- } \\
\text { ing with colleagues from other units'. }\end{array}$ & 5.21 & 1.38 & KT2 \\
\hline 'Making efforts to integrate knowledge from different units'. & 5.27 & 1.55 & KT3 \\
\hline Opportunity formation a ${ }^{\text {a }}$ & 5.63 & 1.01 & OF \\
\hline 'We used the problem to explore or build new possibilities'. & 5.28 & 1.26 & OF1 \\
\hline 'We used the problem to construct new ideas'. & 5.61 & 1.14 & OF2 \\
\hline $\begin{array}{l}\text { 'We saw the problem as an opportunity to improve and } \\
\text { innovate'. }\end{array}$ & 5.99 & 1.04 & OF3 \\
\hline Problem pressure $^{\text {a }}$ & 4.50 & 1.33 & $\mathrm{PP}$ \\
\hline $\begin{array}{l}\text { 'To what extent did the problem exert pressure on the } \\
\text { subsidiary'. }\end{array}$ & 4.99 & 1.39 & PP1 \\
\hline $\begin{array}{l}\text { 'To what extent did the problem exert pressure on the } \\
\text { wider (MNC) organization'. }\end{array}$ & 4.01 & 1.76 & PP2 \\
\hline People involved $\mathrm{b}$ & 2.83 & 0.96 & People \\
\hline Functional diversity $^{\mathrm{c}}$ & 0.42 & 0.35 & FuncDiv \\
\hline Unit risk taking propensity ${ }^{\mathrm{d}}$ & 3.54 & 1.39 & Risk \\
\hline $\begin{array}{l}\text { 'Low risk projects with normal and certain rates of return } \\
\text { vs. High risk projects with unpredictable rates of return'. }\end{array}$ & 3.15 & 1.40 & Risk1 \\
\hline $\begin{array}{l}\text { 'A cautious wait and see posture in order to minimize the } \\
\text { probability of making costly decisions when faced with } \\
\text { uncertainty vs. A bold aggressive posture in order to } \\
\text { maximize the probability of exploiting potential when } \\
\text { faced with uncertainty'. }\end{array}$ & 3.73 & 1.57 & Risk2 \\
\hline $\begin{array}{l}\text { 'Owing to the nature of the environment, it is best to } \\
\text { explore gradually via cautious behaviour vs. Owing to } \\
\text { the nature of the environment, bold wide-ranging acts } \\
\text { are necessary to achieve the firm's objectives'. }\end{array}$ & 3.75 & 1.61 & Risk3 \\
\hline$M N C$ normalization of problem solving ${ }^{\mathrm{e}}$ & 4.98 & 1.46 & NormPS \\
\hline
\end{tabular}


Table III. Continued

\begin{tabular}{lllr}
\hline \hline Construct and indicators & Mean & SD & Label \\
\hline 'Organizational communications signal that non-routine & 4.33 & 1.59 & NormPS1 \\
$\quad$ problems are considered an ordinary occurrence'. & & & NormPS2 \\
'The organization takes non-routine problems in its stride'. & 5.33 & 1.32 & NormPS3 \\
'As far as the organization is concerned, non-routine prob- & 5.27 & 1.76 & \\
$\quad$ lems are not seen as anything extra-ordinary'. & & & \\
\hline \hline
\end{tabular}

Note: $\mathrm{N}=67$.

aAssessed on 7 point Likert scale, ranging from $1=$ 'to a very small extent', to $7=$ 'to a very large extent'.

${ }^{\mathrm{b}} \mathrm{Log}$ transformation of number of people involved.

${ }^{c_{\%}} \%$ people in different function.

${ }^{\mathrm{d}}$ Assessed on a 7 point semantic differential scale.

'Assessed on a 7 point Likert scale, ranging from $1=$ 'strongly disagree', to $7=$ 'strongly agree'.

the established creative performance measure developed by Oldham and Cummings (1996). Following the definition of creativity, the item phrasing highlights that newness and usefulness are both necessary conditions. We adapted the item phrasing to refer to problem solving.

$M N C$ knowledge transformation. MNC knowledge transformation was measured by three items that capture the collaborators' activities of proposing and synthesizing diverse knowledge from MNC units located in other countries to apply it in new ways for the respective problem solving project. The items were developed with reference to descriptions of boundary spanning knowledge processes in co-located organizations (Carlile, 2002, 2004) and MNGs (Tippmann et al., 2012, 2014) as well as additional interviews to gain insights into typical MNC boundary spanning activities (details available from authors). The respondents were asked to indicate 'To what extent did you observe the following activities by the people engaged in the problem solving process?'.

Opportunity formation. Following Alvarez and Barney (2007) we adopt a broad definition of opportunity formation. The three items that measure opportunity formation were derived from descriptions of opportunity formation by Alvarez et al. (2013), and Alvarez and Barney (2008). Opportunity formation was measured by asking the respondents: 'To what extent did you observe the following activities by the people engaged in the problem solving process?'.

Controls. Other factors related to the problem solving and organizational context may influence the degree to which collaborators can achieve creative solutions. We divided our controls into four broad categories consisting of problem characteristics, problem solving group level, subsidiary level, and MNC level controls.

Problem characteristic controls. We controlled for problem pressure as decision situations of high pressure intensity increase the likelihood of calling into question the efficacy of the organization's previous responses (Papadakis et al., 1998), and are more likely to allow creative solution ideas to be pursued. The two items were adapted from Papadakis et al. 
(1998) to suit the problem solving context, and respondents were asked to indicate to what extent the problem exhibited each of two features of pressure. We also examined whether the problem type, i.e., replacing legacy processes, replacing legacy products, or rejuvenating business practices, had an effect on our model. When we included two dummy variables for problem type in our model, we found neither was significant and there was no change to the significance or direction of our variables of interest. Therefore we have presented the more parsimonious model. Additional controls such as project duration and problem complexity were also examined, but as these had no significant effect they are also omitted from our final model.

Problem solving group controls. More radical creativity, which shows high divergence from a firm's current practices or processes, is fostered by resource availability (Madjar et al., 2011). To account for the availability of resources, we took the objective measure of the number of people involved in the project, using its log transformation in our analysis. We also controlled for functional diversity because a certain level of diversity in group composition is expected to provide more varied input and hence increase chances of creative output (e.g., Ancona and Caldwell, 1992). Additional controls were considered for inclusion in our model such as the nature of prior relationships, i.e., the proportion of important collaborators that the project leader had known prior to the problem solving (colleagues previously known); and the extent of competition present between the MNC units of the project leader and important collaborators (coopetition). Neither of these had a significant effect on our variables of interest and are not included in our presented model.

Subsidiary level controls. As the pursuit of creativity entails risk and uncertainty, we control for unit risk taking propensity, adapting the measure established by Covin and Slevin (1989). Similarly to the group level, we examined additional controls at the unit level - subsidiary size (number of employees), subsidiary age, mode of establishment (i.e., greenfield vs. acquisition). These variables were not significant and did not change the direction and significance of our variables of interest, and are thus not included in our final model.

MNC level controls. Some MNGs may provide a more supportive problem solving context to help dissipate the negative connotations that facing non-routine problems can entail. We therefore control for $M \mathcal{N} C$ normalization of problem solving, adapting Shepherd et al.'s (2011) measure to the MNG problem solving context. We also tested additional controls at the MNC level including logged transformations of the number of employees and turnover (2012 US\$) as proxies for MNC size, but found these variables were not significant, and they are not presented here.

An additional model that included controls for problem pressure, people involved, functional diversity, unit risk taking propensity, and $M \mathcal{N} C$ normalization of problem solving on both the solution creativity and opportunity formation variables was also created. As none of the controls had a significant effect on opportunity formation or impacted the direction or significance of our variables of interest they are not included in our final model. ${ }^{[1]}$ 


\section{Data Analysis Method}

To analyse our data we used partial least squares (PLS) which is a variance-based structural equation model (SEM) (Hair et al., 2014). We chose this technique because our study is exploratory and PLS has been shown to be appropriate under these circumstances (Hair et al., 2013). In addition, PLS is suitable for small sample sizes of 30 to 100 cases (our data has 67 observations) (Reinartz et al., 2009). We used SmartPLS 3.0 (Ringle et al., 2015) to compute our model. Our analysis was carried out using the path weighting scheme (Henseler et al., 2012).

\section{RESULTS}

We followed a two-stage process to assess our data and estimate our model. In the first stage, we examined item reliability and internal construct reliability as well as convergent validity and discriminant validity. The item outer loadings for the measures of our reflective constructs were all above the 0.7 suggested cut-off mark (Hair et al., 2014) (see Table IV). As indicated in Table IV, our reflective measures all have construct reliability values above 0.830 , indicating their internal reliability is acceptable. In addition, we examined the convergent validity of our reflective constructs. The average variance extracted (AVE) values (see Table IV) are 0.635 and higher, which is above the 0.500

Table IV. Measurement model evaluation results

\begin{tabular}{|c|c|c|c|}
\hline Constructs & Loading & Composite reliability & $A V E$ \\
\hline Solution creativity (SC) & & 0.839 & 0.635 \\
\hline Original and practical work (SC1) & 0.845 & & \\
\hline Adaptive and practical work (SC2) & 0.747 & & \\
\hline Creative work (SC3) & 0.796 & & \\
\hline$M \mathcal{N} C$ knowledge transformation (KT) & & 0.933 & 0.822 \\
\hline Explain meaning of technical knowledge (KTl) & 0.897 & & \\
\hline Sharing unit-specific knowledge (KT2) & 0.896 & & \\
\hline Integrate knowledge from different units (KT3) & 0.925 & & \\
\hline Opportunity formation $(O F)$ & & 0.908 & 0.768 \\
\hline Used problem to explore new possibilities (OF1) & 0.878 & & \\
\hline Used the problem to construct new ideas (OF2) & 0.925 & & \\
\hline Problem was an opportunity to innovate(OF3) & 0.823 & & \\
\hline Problem pressure $(P P)$ & & 0.830 & 0.710 \\
\hline Problem exerts pressure on subsidiary $(\mathrm{PP} 1)$ & 0.891 & & \\
\hline Problem exerts pressure on organization (PP2) & 0.791 & & \\
\hline Unit risk taking propensity (Risk) & & 0.927 & 0.809 \\
\hline Low vs. high risk projects (Riskl) & 0.800 & & \\
\hline Wait and see vs. aggressive posture (Risk2) & 0.953 & & \\
\hline Cautious behaviour vs. bold wide-ranging acts (Risk3) & 0.936 & & \\
\hline$M \mathcal{N} C$ normalization of problem solving (NormPS) & & 0.931 & 0.820 \\
\hline Non-routine problems are considered ordinary (NormPS1) & 0.758 & & \\
\hline Takes non-routine problems in its stride (NormPS2) & 0.966 & & \\
\hline Non-routine problems are not extra-ordinary (NormPS3) & 0.977 & & \\
\hline
\end{tabular}


Table V. Discriminant validity assessment

\begin{tabular}{|c|c|c|c|c|c|c|c|c|}
\hline Construct & 1 & 2 & 3 & 4 & 5 & 6 & 7 & 8 \\
\hline 1 Solution creativity & 0.797 & & & & & & & \\
\hline 2 MNG knowledge transformation & 0.111 & 0.907 & & & & & & \\
\hline 3 Opportunity formation & 0.409 & 0.594 & 0.876 & & & & & \\
\hline 4 Problem pressure & 0.226 & 0.272 & 0.134 & 0.843 & & & & \\
\hline 5 People involved & -0.223 & 0.176 & -0.026 & 0.364 & 1.000 & & & \\
\hline 6 Functional diversity & 0.099 & 0.098 & 0.044 & -0.107 & -0.095 & 1.000 & & \\
\hline 7 Unit risk taking propensity & 0.128 & 0.145 & 0.098 & 0.156 & -0.091 & -0.306 & 0.899 & \\
\hline $8 \mathrm{MNC}$ normalization of problem solving & 0.109 & 0.014 & -0.055 & 0.085 & -0.176 & -0.364 & 0.611 & 0.906 \\
\hline
\end{tabular}

Note: Diagonal elements are square roots of AVEs, other elements are latent variable correlations.

critical value (Hair et al., 2014) and provides evidence of convergent validity. To check for discriminant validity, we used the Fornell-Larcker criterion in which the correlations of the variables are compared to the square root of the AVE values (Hair et al., 2014). We detail the correlations (off-diagonal values) and the square root of the AVE values (down the diagonal) in Table V. As can be seen, the AVE square root values are higher than the correlations of the constructs which suggests that our constructs have discriminant validity. Further confirmation of discriminant validity included examining the cross-loadings of our indicators. We found that no indicator loaded higher with regards to other constructs.

In the second stage, we created a model to test our hypotheses. To test for the significance of our parameters, we ran a 5000 sub-sample bootstrap with the no-sign changes option. The relationship between $M \mathcal{N} C$ knowledge transformation and opportunity formation is positive and significant $(\beta=0.594, \mathrm{p}<.001)$, which supports Hypothesis 1 . In addition, the relationship between opportunity formation and solution creativity is also positive and significant $(B=0.363, \mathrm{p}<.001)$, giving support for Hypothesis 2. Overall, the model shows a positive indirect effect between $M \mathcal{N} C$ knowledge transformation and solution creativity via opportunity formation (total effect, $\beta=0.216, \mathrm{p}<.001$ ). Table VI details the path coefficients between each of our variables and t-values based upon the bootstrapping procedure. The control variable for problem pressure is positive and significant $(\beta=0.288$, $\mathrm{p}<.05)$, indicating that the more intense the pressure the more creative the solution generated. The control variable for number of people involved is negative and significant $(\beta=-0.289, \mathrm{p}<.05)$, suggesting that the more people that are involved in solving the problem the less creative the solution generated. The control variables for functional diversity, unit risk taking propensity, and $M N C$ normalization of problem solving were not significant. The variance explained for opportunity formation $\left(\mathrm{R}^{2}=0.353\right)$ and solution creativity $\left(\mathrm{R}^{2}=0.300\right)$ suggest that the model has predictive relevance. In addition, we ran the blindfolding procedure (Hair et al., 2014) to obtain Stone-Geisser $Q^{2}$ statistics. The positives values of the Stone-Geisser $Q^{2}$ statistics ( 0.234 and 0.146 respectively) indicate that the model has predictive relevance. In addition, to test the significance of the indirect relationship between $M N C$ knowledge transformation and solution creativity we calculated the Sobel test statistic $(2.946, \mathrm{p}<.01$, two-tailed). 
Table VI. Structural model assessment

\begin{tabular}{lrr}
\hline \hline Endogenous constructs & $R^{2}$ & Stone-Geisser $Q^{2}$ \\
\hline Opportunity formation & 0.353 & 0.234 \\
Solution creativity & 0.300 & 0.146 \\
\hline Relation & Path coefficient & t value (bootstrap) \\
\hline MNG knowledge transformation $\rightarrow$ Opportunity formation & $0.594 * * *$ & 6.340 \\
Opportunity formation $\rightarrow$ Solution creativity & $0.363^{* * *}$ & 3.337 \\
Problem pressure $\rightarrow$ Solution creativity & $0.288^{*}$ & 2.090 \\
People involved $\rightarrow$ Solution creativity & $-0.289 *$ & 2.226 \\
Functional diversity $\rightarrow$ Solution creativity & 0.122 & 0.942 \\
Unit risk taking propensity $\rightarrow$ Solution creativity & 0.002 & 0.011 \\
MNG normalization of problem solving $\rightarrow$ Solution creativity & 0.099 & 0.554 \\
\hline \hline
\end{tabular}

Note: $* \mathrm{p}<0.05, * * \mathrm{p}<0.01, * * * \mathrm{p}<0.001$.

\section{Post-Hoc Tests}

To account for alternative explanations, we also tested a model that included a direct effect between $M N C$ knowledge transformation and solution creativity (results available from the authors). As expected, the direct relationship was not significant ( $\beta=-0.215$, p ns), and its inclusion in our model does not change the significance and direction of our results.

Robustness checks including creating sub-samples of ICT and pharmaceutical industry cases (i.e., removing the three cases from other industries), of Irish subsidiaries only (removing the three cases from outside of Ireland), and including only those with a UK or US parent (removing the four cases where the parent company was from Germany, France and Sweden) respectively, strongly supported our hypotheses (results available from the authors).

As a further test of the effect of $M N C$ knowledge transformation on solution creativity via opportunity formation we conducted the Preacher and Hayes (2004) bootstrap test for indirect effects. The model includes both our variables of interest and our control variables. The results of the analysis indicate a positive and significant direct effect of $M N C$ knoweledge transformation on opportunity formation and a positive and significant direct effect of opportunity formation on solution creativity. Importantly, the indirect effect of $M N C$ knowledge transformation on solution creativity via opportunity formation is also positive and significant as zero is not included in the bias corrected 95 per cent confidence interval with a lower limit of 0.060 and an upper limit of 0.286 (full results of the analysis are available from the authors). We therefore conclude that our model is robust with regard to both PLS analysis (Hair et al., 2014) and the Preacher and Hayes (2004) bootstrap method of analysis.

\section{DISGUSSION}

Despite the importance of boundary spanning for the generation of innovative and creative outcomes, there are still major gaps in our understanding of how MNCs utilize, coordinate and manage knowledge across their geographic locations (Andersson et al., 
2016; Meyer et al., 2011, p. 247). We need to understand not just how such firms integrate their diverse knowledge across boundaries but how they can do so in a way which unlocks its embedded value to achieve innovative and creative solutions. In response, our approach to investigating knowledge transformation in MNGs and its impact on solution creativity allows us to advance theory on boundary spanning and creativity in the MNG.

\section{MNG Knowledge Transformation and MNG Boundary Capability}

Responding to the need to develop the specificities of boundary spanning in global organizations, we draw on Carlile $(2002,2004)$ to suggest that the type of boundary faced by subsidiary and headquarters actors when working together for problem solving is often pragmatic in nature, requiring knowledge transformation. Developing the concept of MNC knowledge transformation, as the extent to which collaborators from across subsidiary and headquarters units propose and apply one another's diverse knowledge in new ways, prompts attention to the critical behavioural aspects of boundary spanning collaboration. Specifically, it emphasizes how collaborators draw on and synthesize expertise that is not only geographically distributed, but can be highly diverse and invested in practice as MNGs nurture specialized knowledge pockets in different institutional environments. Specifying MNC knowledge transformation, this study gives attention to the types of actions and interactions at a micro-social level that in their combination allow collaborators from various subsidiary and headquarters units to benefit from the diverse knowledge of the organization.

Other research concerned with boundary spanning in the MNC has focused on individual boundary spanners (e.g., Barner-Rasmussen et al., 2014; Schotter and Beamish, 2011) and communities of practice (Tallman and Chacar, 2011). Our paper differs in its approach, examining boundary spanning at the group level. Project groups are an increasingly important form of organizing, especially for performing creative and innovative tasks (Obstfeld, 2012). It is thus critical for our understanding of boundary spanning in global organizations to advance theory in this respect. In these temporary and task-specific collaborative situations, MNGs often purposefully bring together individuals from different country units to benefit from diverse knowledge. These situations, however, put an onus on collaborators to effectively overcome the many challenges of crossing boundaries to achieve the envisaged benefits of realizing innovative and creative potential.

In this respect, our findings demonstrate that collaborators' systematic actions can surmount the challenges that spanning pragmatic boundaries in the MNC entails and unleash creative potential. Our interest in collaborators' actions and interactions at a micro-social level thus reveals a collective accomplishment underpinning an organization-level capability (Felin et al., 2012). Building on Carlile's (2004) suggestion that knowledge transformation is the most demanding, yet potentially most value adding boundary spanning activity compared to the less complex activities of knowledge transfer and translation, we propose that MNG knowledge transformation represents one (but not the only) micro-foundation of a MNC boundary capability. Through repeated and iterative actions and interactions, a MNG boundary capability allows the 
organization to not only access its diverse knowledge but to transform this knowledge across its units to achieve innovative and creative outcomes.

\section{The Value of Boundary Spanning: 'Turning' Problems into Opportunities}

Our findings demonstrate that MNC knowledge transformation leads to the generation of creative outcomes, albeit in a more complex way than previously considered. Prior literature on boundary spanning across functions in co-located settings points to the value of knowledge transformation in allowing collaborators to synthesize diverse knowledge in new ways (e.g., Carlile, 2004; Carlile and Rebentisch, 2003), but does not typically explore problem formulation actions in detail. Addressing this oversight, we find support for a mediating effect: MNC knowledge transformation can lead to creative solutions when problems are formed as opportunities. Our findings demonstrate that unlocking the creative potential in problem solving requires collaborators to seek out and apply their collective and diverse expertise when framing the problem. Although extant literature on problem solving emphasizes problem definition (Lyles, 1981; Lyles and Mitroff, 1980) and points towards the importance of introducing diversity in perspectives during problem formulation to conceptualize the situation more comprehensively (Baer et al., 2013), our findings suggest that the problem can also be considerably redefined. MNC knowledge transformation can generate creative solutions by facilitating alternative formulations of the problem; it is a means to break out of 'habitual' problem definitions (Ford, 1996) that too often constrain the attainment of truly novel and useful solutions. By revealing this mediating relationship, our findings offer new insights into how the influence of knowledge transformation is transmitted to enable the generation of creative outcomes. For the MNC, this finding offers interesting implications: problem formulations can constrain subsidiary value creation if they are narrow and context-specific. However, MNG knowledge transformation offers the possibility of generating a reframed perspective on organizational challenges, revealing previously unforeseen opportunities for not just firm value creation, but potentially for building entrepreneurship across the MNC.

\section{Greativity within the MNG}

In environments where competition is increasingly based on novel ideas packaged in innovative products, services or processes, creative solutions are required to rejuvenate and sustain established firms. These solutions can be a source of firm advantage if they unlock unique ideas and reveal value creating responses to usually complex and illdefined challenges (Kim et al., 2013; Reiter-Palmon and Illies, 2004).

In most firms, creative responsibility is distributed across units and levels. Driven by the geographic dispersion of operations and the need to tap into location-specific advantages, it is recognized that creative potential is highly distributed within MNCs (Cantwell and Mudambi, 2005; Nohria and Ghoshal, 1997) and achieving creative outcomes is a critical subsidiary contribution to rejuvenating the MNC's sources of advantage. Despite the acceptance that subsidiaries can be engines for the generation of creative solutions due to their capacity to combine knowledge in unexpected ways (Cantwell and 
Mudambi, 2005, 2011), there is a paucity of research investigating the different ways such creative solutions are achieved.

Our research addresses this gap, clearly demonstrating how opportunity formation operates as a mechanism to unlock the value of knowledge transformation and enables subsidiaries to generate creative solutions. This sheds valuable light on a previously hidden relationship and shows that creative outcomes in the MNG can be the result of a collective activity spanning different units. The collective framing of a problem as an opportunity for the generation of creative solutions aligns well with suggestions that creativity can be a collective-level phenomenon arising through the interaction between individuals (George, 2007; Hargadon and Bechky, 2006; Sonenshein, 2014). Although competence creating subsidiaries may have a higher potential for creative solution development compared to competence implementing subsidiaries (Cantwell and Mudambi, 2005), our findings demonstrate that the development of creative solutions is not confined to a certain subsidiary type.

\section{Opportunity Formation}

Another contribution of our study is to theory on the phenomenon of opportunity. Despite growing recognition that opportunities are the outcome of social construction and are enacted subjectively (Alvarez and Barney, 2007; Alvarez et al., 2013), much of the literature continues to treat opportunity related processes as a 'black box' (Alvarez et al., 2013; Hansen et al., 2011). Our research shows that non-routine problems can be used to trigger new ideas and possibilities when knowledge transformation occurs, i.e., collaborators working together can construct an opportunity from what was originally an obstacle. Instead of focusing on individual differences in personality or cognitive abilities, our findings suggest that collective boundary spanning activities matter, especially collaborators' engagement in knowledge transformation. This substantiates conjectures that knowledge processes are critical to forming opportunities (Lumpkin and Lichtenstein, 2005), suggesting rich potential for future studies to explore problem solving and opportunity formation in a broader entrepreneurial context.

\section{Implications for Practice}

Although many managers are aware of the value of boundary spanning in generating creative solutions, they may be less familiar with how to unlock the potential of knowledge diversity. In the context of the MNC, where knowledge pockets are not only distributed but also highly specialized and invested in practice, converting diversity of knowledge into tangible value is especially challenging. Our study provides several valuable insights for managers operating in such contexts.

MNGs rely on their networks of subsidiaries to recognize new opportunities and to bring these to headquarters' attention (Andersson et al., 2007). We show that for subsidiaries, opportunities can arise in unexpected places, when an entrepreneurial approach is taken to shaping challenges. This is a valuable insight into alternative means for subsidiaries to contribute to their MNC, especially for those subsidiary managers operating in competence implementing subsidiaries, with little scope to engage in the autonomous entrepreneurial behaviour typical of strategic initiative generation (Birkinshaw et al., 
1998). In a similar vein, developing creative solutions to organizational challenges has the potential to address a key tension within MNCs. On the one hand headquarters expects its subsidiaries to put forward new ideas, but on the other hand each unit is required to focus its resources and capabilities on achieving its specific mandate. Utilizing challenging or atypical situations to provide creative solutions for the organization provides subsidiary managers with a valuable option to demonstrate the value of their unit without moving too far outside of the assigned mandate.

In addition, our findings suggest a critical role for the MNC in setting a context that supports not just the development of a boundary capability and knowledge transformation across its operations but also an entrepreneurial approach to problem solving to encourage creative reshaping or reframing of problems (Hargadon and Bechky, 2006). In this respect, the insight that opportunity formation is an underlying mechanism linking knowledge transformation and the development of creative solutions offers important guidance regarding the problem solving approach to adopt when creative solutions are desired. We contend that how the problem is formulated can impact achievement of creative outcomes. Problem formulation is often superficial and lacks debate (Baer et al., 2013; Lyles, 1981) - solution finding commences in a rush to implement remedies quickly. Early efforts to transform knowledge are advisable as they can lead to new formulations of the problem that open previously unconceived solution ideas.

It is important that executive managers recognize the value of attaining creative solutions. Greater value creation and advantage to the organization can be achieved if problems are approached in a way which encourages the development of not just an effective solution but one that produces a novel and useful outcome. For example, organizations operating in the same industry often face similar business challenges. The capability to generate creative solutions that competitors have not envisioned builds valuable and rare resources (Kim et al., 2013), ultimately strengthening the firm's competitive advantage. In addition, the causal ambiguity of forming opportunities, as implied by the complex pattern and iterative nature of knowledge transformation activities at boundaries, may in itself become a source of firm advantage (Alvarez et al., 2013). In this respect, for MNCs, our results are encouraging regarding the ability of subsidiary driven problem solving, particularly through boundary spanning, to create solutions that are not 'just' workable, but of high creative value.

Last but not least, our work clearly demonstrates the value of boundary capabilities to support knowledge amplification across the MNC. However, managers should not underestimate the efforts required by collaborators to achieve effective knowledge transformation. Understanding the specific expertise, technical language, styles and potentially conflicting views of other collaborators requires both time and considerable effort, but as our results show, it is critical to unlocking the benefits of diverse MNC knowledge.

\section{Limitations and Avenues for Future Research}

This study has limitations that create avenues for future research. As our study was concerned with subsidiary driven problem solving processes, our sample does not include problem solving projects initiated at the corporate or headquarters level. It may be the 
case that problems identified as requiring resolution at these levels exhibit higher pressure and therefore pose more demands on knowledge transformation and opportunity formation behaviours to lead to creative solutions. Future research can meaningfully extend our arguments to these scenarios.

Our interest in examining the links between problem solving activities and creative outcomes required sampling problem solving projects where solutions were implemented. Although our sample exhibits good variation in the level of creative solutions generated, our study may under-represent less formalized problem solving processes and certainly excludes processes that were terminated early. As organizational problems are typically only addressed after undergoing a stage of creeping awareness until a tipping point is reached (Lyles, 1981; Lyles and Mitroff, 1980), more research is needed to understand the influence of knowledge transformation during this very early phase of problem formulation and how knowledge transformation can help ensure that the 'right' organizational challenges are prioritized for resolution. More work is also needed to understand the iterative nature of problem solving.

In relation to boundary spanning in global organizations, our study was focused on MNC knowledge transformation as the most critical boundary spanning activity in atypical situation. As outlined earlier, Carlile (2002, 2004) proposes two other boundary spanning activities - knowledge transfer and knowledge translation. While there is considerable research on knowledge transfer in the MNC, there is considerable scope for research to further examine the translation and transformation of knowledge at semantic and pragmatic boundaries, respectively. In addition, future research could explore alternative mechanisms through which the benefits of MNC knowledge transformation are transmitted. Beyond opportunity formation, this may include the capacity of collaborators from across the MNC to agree on a joint problem definition that avoids the danger of powerful individuals or coalitions to pre-dominate (e.g., Baer et al., 2013) and hence hinder the benefit of knowledge transformation to materialize.

Our sampling strategy was broad as we chose MNCs and subsidiaries that exhibited variation in organizational attributes. We also studied problem solving projects from varied functional areas. This minimizes the likelihood that our findings are the result of a certain organizational context, increasing the generalizability of our findings. However, our sample is largely focused on two industries (ICT and pharmaceutical) and subsidiaries located in one country. Future work can meaningfully extend our findings to other industries and locations. Although our sample size is relatively small, it is still sufficient to provide the necessary power to test our hypotheses and control for important extraneous factors. However, it does not allow us to examine systematically all constellations of extraneous factors.

Although we obtained information on solution creativity from an independent evaluator to reduce common method bias, this information was usually provided by a subsidiary manager. While the subsidiary top managers' relative closeness to current solutions and high international exposure support their ability to answer these questions accurately, corroboration with a headquarters' evaluation, however, may allow an even wider assessment of the newness and usefulness of the solution. We also implemented a range of techniques to limit recall issues in relation to reporting on past projects. These included a 12 months cut-off time-frame to include only processes of the recent past, 
focusing on specific activities surrounding a concrete event (specific problem solving project), ensuring confidentiality, detailed explanation of study benefits and researcher administration of the survey to ensure respondents reflected carefully on each question.

\section{GONGLUSION}

As the MNG represents an organizational setting characterized by high levels of knowledge diversity, developing a boundary capability is not only critical for the generation of creative solutions but also for MNG advantage. By showing that MNC knowledge transformation can give rise to opportunity formation for the development of creative solutions, this study advances our understanding of how to liberate the often untapped potential of diverse knowledge within the MNC.

\section{ACKNOWLEDGEMENTS}

This study was funded by the Irish Research Council with co-funding from the European Commission (Marie-Curie Fellowship). We are very grateful for the insightful comments of Phillip C. Nell, the three reviewers, editors and participants at the paper development workshop at Ivey Business School.

\section{NOTE}

[1] When including the additional controls in the model the effect of our control for problem pressure on solution creativity was no longer significant.

\section{REFERENGES}

Aldrich, H. E. and Martinez, M. A. (2010). 'Entrepreneurship as social construction: A multilevel evolutionary approach'. In Acs, Z. J. and Audretsch, D. B. (Eds), Handbook of Entrepreneurship Research: An Interdisciplinary Survey and Introduction. New York: Springer Science \& Business Media, 387-427.

Alvarez, S. A. and Barney, J. B. (2007). 'Discovery and creation: Alternative theories of entrepreneurial action'. Strategic Entrepreneurship Fournal, 1, 11-26.

Alvarez, S. A. and Barney, J. B. (2008). 'Opportunities, organizations, and entrepreneurship'. Strategic Entrepreneurship Fournal, 2, 265-7.

Alvarez, S. A., Barney, J. B. and Anderson, P. (2013). 'Forming and exploiting opportunities: The implications of discovery and creation processes for entrepreneurial and organizational research'. Organization Science, 24, 301-17.

Amabile, T. M. (1996). Creativity in Context: Update to the Social Psychology of Creativit'. Boulder, CO: Westview.

Ancona, D. G. and Caldwell, D. F. (1992). 'Demography and design: Predictors of new product team performance'. Organization Science, 3, 321-41.

Andersson, U., Forsgren, M. and Holm, U. (2007). 'Balancing subsidiary influence in the federative MNC: A business network view'. Fournal of International Business Studies, 38, 802-18.

Andersson, U., Dasi, A., Mudambi, R. and Pedersen, T. (2016). 'Technology, innovation and knowledge: The importance of ideas and international connectivity'. Fournal of World Business, 51, 153-62.

Baer, M., Dirks, K. T. and Nickerson, J. A. (2013). 'Microfoundations of strategic problem formulation'. Strategic Management Fournal, 34, 197-214.

Barner-Rasmussen, W., Ehrnrooth, M., Koveshnikov, A. and Mäkelä, K. (2014). 'Cultural and language skills as resources for boundary spanning within the MNC'. Fournal of International Business Studies, $\mathbf{4 5}$, 886-905.

Barreto, I. (2012). 'Solving the entrepreneurial puzzle: The role of entrepreneurial interpretation in opportunity formation and related processes'. Fournal of Management Studies, 49, 356-80.

Bartlett, G. A. and Ghoshal, S. (1989). Managing Across Borders: The Transnational Solution. Boston, MA: Harvard Business School Press. 
Bechky, B. A. (2003). 'Sharing meaning across occupational communities: The transformation of understanding on a production floor'. Organization Science, 14, 312-30.

Beck, T. E. and Plowman, D. A. (2009). 'Experiencing rare and unusual events richly: The role of middle managers in animating and guiding organizational interpretation'. Organization Science, 20, 909-24.

Berry, H. (2014). 'Global integration and innovation: Multicountry knowledge generation within MNCs'. Strategic Management fournal, 35, 869-90.

Birkinshaw, J., Ambos, T. and Bouquet, C. (2017). 'Boundary spanning activities of corporate HQ executives: Insights from a longitudinal study'. Fournal of Management Studies, 54, 422-54.

Birkinshaw, J., Hood, N. and Jonsson, S. (1998). 'Building firm-specific advantages in multinational corporations: The role of subsidiary initiative'. Strategic Management Fournal, 19, 221-41.

Birkinshaw, J. and Ridderstrale, J. (1999). 'Fighting the corporate immune system: A process study of subsidiary initiatives in multinational corporations'. International Business Review, 8, 149-80.

Burgelman, R. A. (1983). 'A process model of internal corporate venturing in the diversified major firm'. Administrative Science Quarterly, 28, 223-44.

Cantwell, J. and Mudambi, R. (2005). 'MNE competence-creating subsidiary mandates'. Strategic Management fournal, 26, 1109-28.

Cantwell, J. and Mudambi, R. (2011). 'Physical attraction and the geography of knowledge sourcing in multinational enterprises'. Global Strategy Fournal, 1, 206-32.

Carlile, P. R. (2002). 'A pragmatic view of knowledge and boundaries: Boundary objects in new product development'. Organization Science, 13, 442-55.

Carlile, P. R. (2004). 'Transferring, translating, and transforming: An integrative framework for managing knowledge across boundaries'. Organization Science, 15, 555-68.

Carlile, P. R. and Rebentisch, E. S. (2003). 'Into the black box: The knowledge transformation cycle'. Management Science, 49, 1180-95.

Ciabuschi, F., Dellestrand, H. and Martín, O. M. (2011). 'Internal embeddedness, headquarters involvement, and innovation importance in multinational enterprises'. Fournal of Management Studies, 48 , $1612-39$.

Collins, D. (2005). 'A synthesis process model of creative thinking in music composition'. Psychology of Music, 33, 193-216.

Covin, J. G. and Slevin, D. P. (1989). 'Strategic management of small firms in hostile and benign environments'. Strategic Management Fournal, 10, 75-87.

Cyert, R. M. and March, J. G. (1963). Behavioral Theory of the Firm. Englewood Cliffs, NJ: Prentice Hall Inc.

Dörrenbächer, C. and Gammelgaard, J. (2006). 'Subsidiary role development: The effect of micropolitical headquarters-subsidiary negotiations on the product, market and value-added scope of foreign-owned subsidiaries'. Fournal of International Management, 12, 266-83.

Dougherty, D. (1992). 'Interpretive barriers to successful product innovation in large firms'. Organization Science, 3, 179-202.

Doz, Y. L., Santos, J. and Williamson, P. (2001). From Global to Metanational: How Companies Win in the Knoweledge Economy. Boston, MA: Harvard Business School Press.

Dutton, J. E. and Ashford, S. J. (1993). 'Selling issues to top management'. Academy of Management Reviere, 18, $397-428$.

Eckhardt, J. T. and Shane, S. A. (2003). 'Opportunities and entrepreneurship'. Fournal of Management, 29, 333-49.

Enders, A., König, A. and Barsoux, J. L. (2016). 'Stop jumping to solutions!'. Sloan Management Review, 57, $62-70$.

Erkelens, R., van den Hooff, B., Huysman, M. and Vlaar, P. (2015). 'Learning from locally embedded knowledge: Facilitating organizational learning in geographically dispersed settings'. Global Strategy Fournal, 5, 177-97.

Felin, T., Foss, N. J., Heimeriks, K. H. and Madsen, T. L. (2012). 'Microfoundations of routines and capabilities: Individuals, processes, and structures'. Fournal of Management Studies, 49, 1351-74.

Felin, T. and Zenger, T. R. (2016). 'Crossroads: Strategy, problems, and a theory for the firm'. Organization Science, 27, 222-31.

Ford, C. M. (1996). 'A theory of individual creative action in multiple social domains'. Academy of Management Review, 21, 1112-42.

Ford, C. M. (2002). 'The futurity of decisions as a facilitator of organizational creativity and change'. Journal of Organizational Change Management, 15, 635-46. 
Galbraith, J. (1973). Designing Complex Organizations. London: Addison-Westley Publishing Company.

Gavetti, G. and Levinthal, D. (2000). 'Looking forward and looking backward: Cognitive and experiential search'. Administrative Science Quarterly, 45, 113-37.

George, J. M. (2007). 'Creativity in organizations'. Academy of Management Annals, 1, 439-77.

Ghemawat, P. (2001). 'Distance still matters. The hard reality of global expansion'. Harvard Business Review, 79, 137-47.

Ghoshal, S. and Bartlett, C. A. (1990). 'The multinational corporation as an interorganizational network'. Academy of Management Review, 15, 603-25.

Godart, F., Maddux, W., Shipilov, A. and Galinsky, A. (2015). 'Fashion with a foreign flair: Professional experiences abroad facilitate the creative innovations of organizations'. Academy of Management Fournal, 58, 195-220.

Gupta, A. K. and Govindarajan, V. (2000). 'Knowledge flows within multinational corporations'. Strategic Management Fournal, 21, 473-96.

Hair, J. F., Ringle, C. M. and Sarstedt, M. (2013). 'Partial least squares structural equation modeling: Rigorous applications, better results and higher acceptance'. Long Range Planning, 46, 1-12.

Hair, J. F. J., Hult, G. T. M., Ringle, C. and Sarstedt, M. (2014). A Primer on Partial Least Squares Structural Equation Modeling (PLS-SEM). Thousand Oaks, CA: Sage.

Hansen, D. J., Shrader, R. and Monllor, J. (2011). 'Defragmenting definitions of entrepreneurial opportunity'. Fournal of Small Business Management, 49, 283-304.

Hargadon, A. B. and Bechky, B. A. (2006). 'When collections of creatives become creative collectives: A field study of problem solving at work'. Organization Science, 17, 484-500.

Henseler, J., Ringle, C. and Sarstedt, M. (2012). 'Using partial least squares path modeling in advertising research: Basic concepts and recent issues'. In Okazaki, S. (Ed.), Handbook of Research on International Advertising. Cheltenham: Edward Elgar Publishing, 252-76.

Huber, G. P. and Power, D. J. (1985). 'Retrospective reports of strategic-level managers: Guidelines for increasing their accuracy'. Strategic Management Fournal, 6, 171-80.

Kim, N., Im, S. and Slater, S. F. (2013). 'Impact of knowledge type and strategic orientation on new product creativity and advantage in high-technology firms'. Fournal of Product Innovation Management, 30, $136-53$.

Kogut, B. and Zander, U. (1993). 'Knowledge of the firm and the evolutionary theory of the multinational corporation'. Fournal of International Business Studies, 24, 625-45.

Kostova, T. and Zaheer, S. (1999). 'Organizational legitimacy under conditions of complexity: The case of the multinational enterprise'. Academy of Management Review, 24, 64-81.

Lawrence, P. and Lorsch, J. (1967). Organizations and Environments: Managing Differentiation and Integration. Boston, MA: Harvard Business School Press.

Leonard-Barton, D. (1995). Wellsprings of Knowledge: Building and Sustaining the Sources of Innovation. Boston, MA: Harvard Business Press.

Leonardi, P. M. (2011). 'Innovation blindness: Culture, frames, and cross-boundary problem construction in the development of new technology concepts'. Organization Science, 22, 347-69.

Levina, N. and Vaast, E. (2005). 'The emergence of boundary spanning competence in practice: Implications and use of information systems'. MIS Quarterly, 29, 335-63.

Lopez-Vega, H., Tell, F. and Vanhaverbeke, W. (2016). 'Where and how to search? Search paths in open innovation'. Research Policy, 45, 125-36.

Lumpkin, G. T. and Lichtenstein, B. B. (2005). 'The role of organizational learning in the opportunityrecognition process'. Entrepreneurship Theory and Practice, 29, 451-72.

Luo, Y. (2005). 'Toward coopetition within a multinational enterprise: A perspective from foreign subsidiaries'. Fournal of World Business, 40, 71-90.

Lyles, M. A. (1981). 'Formulating strategic problems: Empirical analysis and model development'. Strategic Management Fournal, 2, 61-75.

Lyles, M. A. and Mitroff, I. I. (1980). 'Organizational problem formulation: An empirical study'. Administrative Science Quarterly, 25, 102-19.

Madjar, N., Greenberg, E. and Chen, Z. (2011). 'Factors for radical creativity, incremental creativity, and routine, noncreative performance'. Fournal of Applied Psychology, 96, 730-43.

McGrath, R. G. (2001). 'Exploratory learning, innovative capacity, and managerial oversight'. Academy of Management fournal, 44, 118-31.

Meyer, K. E., Mudambi, R. and Narula, R. (2011). 'Multinational enterprises and local contexts: The opportunities and challenges of multiple embeddedness'. Fournal of Management Studies, 48 , $235-52$. 
Mintzberg, H. and Westley, F. (2001). 'Decision making: It's not what you think'. Sloan Management Review, 42, 89-93.

Mitchell, R. K., Mitchell, J. R. and Smith, J. B. (2008). 'Inside opportunity formation: Enterprise failure, cognition, and the creation of opportunities'. Strategic Entrepreneurship Fournal, 2, 225-42.

Mors, M. L. (2010). 'Innovation in a global consulting firm: When the problem is too much diversity'. Strategic Management fournal, 31, 841-72.

Mudambi, R. (2011). 'Hierarchy, coordination, and innovation in the multinational enterprise'. Global Strategy fournal, 1, 317-23.

Mudambi, R., Mudambi, S. M. and Navarra, P. (2007). 'Global innovation in MNCs: The effects of subsidiary self-determination and teamwork'. Fournal of Product Innovation Management, 24, 442-55.

Mudambi, R. and Swift, T. (2009). 'Professional guilds, tension and knowledge management'. Research Policy, 38, 736-45.

Nelson, R. R. and Winter, S. G. (1982). An Evolutionary Theory of Economic Change. Cambridge, MA: The Belknap Press of Harvard University Press.

Newell, A. and Simon, H. A. (1972). Human Problem Solving. Englewood Cliffs, NJ: Prentice-Hall.

Nickerson, J., Yen, C. J. and Mahoney, J. T. (2012). 'Exploring the problem-finding and problem-solving approach for designing organizations'. Academy of Management Perspectives, 26, 52-72.

Nickerson, J. A. and Zenger, T. R. (2004). 'A knowledge-based theory of the firm - The problemsolving perspective'. Organization Science, 15, 617-32.

Nohria, N. and Ghoshal, S. (1997). The Differentiated Network: Organizing Multinational Corporations for Value Creation. San Francisco, CA: Jossey-Bass Publishers.

Nonaka, I. (1994). 'A dynamic theory of organizational knowledge creation'. Organization Science, 5, 14-37.

Noorderhaven, N. and Harzing, A. W. (2009). 'Knowledge-sharing and social interaction within MNEs'. Fournal of International Business Studies, 40, 719-41.

Nutt, P. C. (1984). 'Types of organizational decision processes'. Administrative Science Quarterly, 29, 414-50.

Nutt, P. C. (1992). 'Formulation tactics and the success of organizational decision making'. Decision Sciences, 23, 519-40.

Nutt, P. C. (1993). 'The formulation processes and tactics used in organizational decision making'. Organization Science, 4, 226-51.

Nutt, P. C. (2004). 'Expanding the search for alternatives during strategic decision-making'. Academy of Management Executive, 18, 13-28.

Nutt, P. G. (2005). 'Search during decision making'. European Fournal of Operational Research, 160, 851-76.

Obstfeld, D. (2012). 'Creative projects: A less routine approach toward getting new things done'. Organization Science, 23, 1571-92.

Oldham, G. R. and Cummings, A. (1996). 'Employee creativity: Personal and contextual factors at work'. Academy of Management fournal, 39, 607-34.

Papadakis, V. M., Lioukas, S. and Chambers, D. (1998). 'Strategic decision-making processes: The role of management and context'. Strategic Management fournal, 19, 115-47.

Parker, A. and Tippmann, E. (2016). 'Utilizing diverse knowledge for problem solving in the MNC: A network mobilization perspective'. In Humphreys, J. (Ed.), Proceedings of the Seventy-Sixth Annual Meeting of the Academy of Management. Online ISSN: 2151-6561.

Pawlowski, S. D. and Robey, D. (2004). 'Bridging user organizations: Knowledge brokering and the work of information technology professionals'. MIS Quarterly, 28, 645-72.

Perry-Smith, J. E. and Shalley, C. E. (2003). 'The social side of creativity: A static and dynamic social network perspective'. Academy of Management Review, 28, 89-106.

Preacher, K. J. and Hayes, A. F. (2004). 'SPSS and SAS procedures for estimating indirect effects in simple mediation models'. Behavior Research Methods, Instruments, E Computers, 36, 717-31.

Reinartz, W., Haenlein, M. and Henseler, J. (2009). 'An empirical comparison of the efficacy of covariance-based and variance-based SEM'. International fournal of Research in Marketing, 26, 332-44.

Reiter-Palmon, R. and Illies, J. J. (2004). 'Leadership and creativity: Understanding leadership from a creative problem-solving perspective'. Leadership Quarterly, 15, 55-77.

Ringle, C., Wende, S. and Becker, J. M. (2015). SmartPLS3. Boenningstedt: SmartPLS GmbH. Available at http://www.smartpls.com (Accessed 1 July 2016).

Rugman, A. M., Verbeke, A. and Wenlong, Y. (2011). 'Re-conceptualizing Bartlett and Ghoshal's classification of national subsidiary roles in the multinational enterprise'. Fournal of Management Studies, $\mathbf{4 8}$, 253-77. 
Sarasvathy, S. D., Dew, N., Velamuri, S. R. and Venkataraman, S. (2010). 'Three views of entrepreneurial opportunity'. In Acs, Z. J. and Audretsch, D. B. (Eds), Handbook of Entrepreneurship Research: An Interdisciplinary Survey and Introduction. New York: Springer Science \& Business Media, 77-96.

Schotter, A. and Beamish, P. W. (2011). 'Performance effects of MNC headquarters subsidiary conflict and the role of boundary spanners: The case of headquarter initiative rejection'. Foumal of International Management, 17, 243-59.

Schotter, A., Mudambi, R., Doz, Y. and Gaur, A. (2017). 'Boundary spanning in global organizations'. Fournal of Management Studies, 54, 403-21.

Scott, P., Gibbons, P. and Coughlan, J. (2010). 'Developing subsidiary contribution to the MNC: Subsidiary entrepreneurship and strategy creativity'. Fournal of International Management, 16, 328-39.

Shepherd, D. A., Patzelt, H. and Wolfe, M. (2011). 'Moving forward from project failure: Negative emotions, affective commitment, and learning from the experience'. Academy of Management Fournal, 54, 1229-59.

Simon, H. A. (1973). 'The structure of ill structured problems'. Artificial Intelligence, 4, 181-201.

Simon, H. A. and Hayes, J. R. (1976). 'The understanding process: Problem isomorphs'. Cognitive Psychology, 8, 165-90.

Spradlin, D. (2012). 'Are you solving the right problem?' '. Harvard Business Review, 90, 84-93.

Sonenshein, S. (2014). 'How organizations foster the creative use of resources'. Academy of Management Journal, 57, $814-48$.

Szulanski, G. (1996). 'Exploring internal stickiness: Impediments to the transfer of best practice within the firm'. Strategic Management Fournal, 17, 27-43.

Tallman, S. and Chacar, A. S. (2011). 'Knowledge accumulation and dissemination in MNEs: A practice-based framework'. Fournal of Management Studies, 48, 278-304.

Tippmann, E., Sharkey Scott, P. and Mangematin, V. (2012). 'Problem solving in MNGs: How local and global solutions are (and are not) created'. Fournal of International Business Studies, 43, 746-71.

Tippmann, E., Sharkey Scott, P. and Mangematin, V. (2014). 'Subsidiary managers' knowledge mobilizations: Unpacking emergent knowledge flows'. Fournal of World Business, 49, 431-43.

Tsai, W. (2002). 'Social structure of "coopetition" within a multiunit organization: Coordination, competition, and intraorganizational knowledge sharing'. Organization Science, 13, 179-90.

van Wijk, R., Jansen, J. J. P. and Lyles, M. A. (2008). 'Inter- and intra-organizational knowledge transfer: A meta-analytic review and assessment of its antecedents and consequences'. Fournal of Management Studies, 45, 830-53.

Volkema, R. J. (1983). 'Problem formulation in planning and design'. Management Science, 29, 639-52. 